\title{
Bibliometric analysis of research on thyroid ultrasonography
}

\author{
Juan $\mathrm{Su}^{1}$, Guanghui $\mathrm{Gao}^{2}$, Hongxia $\mathrm{Xu}^{1}$ \\ ${ }^{1}$ Department of Ultrasonography, Jinan Central Hospital, Jinan, China; ${ }^{2}$ Deparment of Surgery, The Third Hospital of Jinan, Jinan, China \\ Contributions: (I) Conception and design: J Su, H Xu; (II) Administrative support: G Gao; (III) Provision of study materials or patients: J Su; (IV) \\ Collection and assembly of data: J Su, G Gao; (V) Data analysis and interpretation: J Su, H Xu; (VI) Manuscript writing: All authors; (VII) Final \\ approval of manuscript: All authors. \\ Correspondence to: Hongxia Xu. Department of Ultrasonography, Jinan Central Hospital, No. 105 Jiefang Road, Lixia District, Jinan 250012, China. \\ Email: hongxiax@126.com.
}

Background: The incidence of thyroid diseases has increased, which may be partly related to the widespread use of thyroid ultrasound resulting in a large number of asymptomatic thyroid nodules to be found. Research has found that many thyroid ultrasound examinations are completely avoidable. However, the purpose of the present study was to use bibliometrics to analyze the relevant research literature of thyroid ultrasound and understand the overall status of the current research in this field.

Methods: We searched the Science Citation Index Expanded (SCI-E) database in the Web of Science Core Collection. Search terms were "ultrasonography" and "thyroid gland". The date range for the document search was from 1900 to May 10, 2021. Export the full record of the search results and the references in txt. format, and use the CiteSpace software to analyze the annual publication of literatures, the distribution of countries and institutions where the literatures came from, the distribution of journals and authors. The keywords used in the literature were also analyzed.

Results: A total of 1,241 publications were included in the results, and the frequency of citations was 27,149. The top 5 countries for the number of publications published were the USA, Turkey, Italy, South Korea, and China; the top 5 countries by centrality were the USA, Germany, Italy, Canada, and China. The number of institution-published papers was generally low, and the centrality score was low. Research in this field was relatively scattered among institutions and cooperation between institutions was few. There was little collaboration between authors from different institutions. The most cited authors were mainly from European and North American countries. Journals, such as Thyroid, Fournal of Clinical Ultrasound, and Journal of Endocrinological Investigation, had great influence in this field. Keyword analysis results showed that research is mainly focused on the differentiation of benign and malignant thyroid nodules.

Conclusions: There was an increase in thyroid ultrasound research, but there was few cooperation exist between institutions. The main research direction was the differentiation of benign and malignant thyroid nodules.

Keywords: Thyroid; ultrasonography; thyroid nodules; thyroid cancer; bibliometrics

Submitted Sep 22, 2021. Accepted for publication Dec 15, 2021.

doi: 10.21037/gs-21-799

View this article at: https://dx.doi.org/10.21037/gs-21-799

\section{Introduction}

In recent years, the incidence of thyroid diseases has increased $(1,2)$, which may be partly related to the widespread use of thyroid ultrasonography resulting in a large number of asymptomatic thyroid nodules to be discovered $(2,3)$. Incidence and prevalence are related to the population under investigation and the method of investigation and inspection, and show a relatively obvious regional distribution (4). As people pay more and more attention to diseases, especially in recent years, the prevalence of annual physical examinations has enabled 
Table 1 Articles included in the present study

\begin{tabular}{lcc}
\hline Type of literature & Number of records & Percentage of 1,241 \\
\hline Article & 1,144 & 92.2 \\
$\begin{array}{l}\text { Conference } \\
\text { proceedings }\end{array}$ & 71 & 5.7 \\
Review article & 71 & 5.7 \\
Editorials & 17 & 1.4 \\
Early access article & 6 & 0.5 \\
Meeting abstract & 4 & 0.3 \\
Book chapter & 3 & 0.2 \\
Letter to the editor & 2 & 0.2 \\
Note & 2 & 0.2 \\
News item & 1 & 0.1 \\
\hline
\end{tabular}

There were 1,321 extracted records, of which 80 were duplicate records. After removal of duplicates, 1,241 documents remained. But the duplicate records were kept in this table.

a large number of thyroid ultrasound examinations to be performed. With the focus on thyroid nodules, a large number of studies have used ultrasound examinations to evaluate these (5). Some studies have conducted indepth analyses on thyroid adenoma and thyroid cancer (6-8). However, the extensive use of thyroid ultrasound has also triggered extensive discussions, mainly focusing on whether it is necessary for some patients to undergo thyroid ultrasound examination (9). Research has shown that many thyroid ultrasound examinations are completely avoidable (10). However, some studies have found that thyroid ultrasound can optimize the management of thyroid cancer and improve prognosis (11). However, even for suspected patients, the risk of thyroid cancer should be fully assessed before performing thyroid ultrasound to avoid over-examination and treatment (12). Based on the results of these previous studies, it is necessary to analyze the related research on thyroid ultrasound to understand the overall situation of the current related research. Bibliometrics is a new quantitative study of related literature on a specific topic in recent years. Through statistical analysis of related literature on a certain topic, we can understand the current research status of the topic and present important related issues for future research, including the distribution of countries, research institutions, and researchers currently conducting research on a subject, important journals, and the cooperation status of relevant research teams (13). Science Citation Index Expanded (SCI-E) database in the Web of Science Core Collection is the most common database used in bibliometrics analysis. The purpose of the present study was to use bibliometrics based on SCI-E database to analyze the relevant research on thyroid ultrasound, and to understand the overall status of the current research in this field.

\section{Methods \\ Databases}

We used the SCI-E database in the Web of Science Core Collection for the article search.

\section{Search strategy}

The following subject terms were used in the present study: "ultrasonography" and "thyroid gland". The date range for document retrieval was from 1900 to May 10, 2021.

\section{Search result analysis}

Export the full records of the search results and related references in txt. format as file for further analysis, and use the CiteSpace software (version 5.7.R2.7z) to analyze the file in the following aspects: the annual literature publication, and the distribution of the source countries/ institutions. the distribution of the journals of the published literatures, the distribution of the authors of the literatures, and the keywords used in the literatures.

\section{Statistical analysis}

The present study describes the current situation of research in thyroid ultrasonography, using absolute numbers and percentages, and the trend and distribution of changes, and does not involve comparisons between groups.

\section{Results}

A total of 1,321 records were searched. After removal of duplicate records, a total of 1,241 publications were used for analysis, including 1,144 original articles, 71 conference papers, 71 reviews, 17 editing materials, 6 articles for priority publication, and 4 conference abstracts, 3 books, 2 letters from the author, 2 notes, 1 news, among which 80 literatures were categorized repeatedly (Tables 1,2; Figure 1). 
Table 2 Annual distribution of the number of publications

\begin{tabular}{|c|c|c|}
\hline Years & Number of records & Percentage of 1,241 \\
\hline 2021 & 13 & 1.0 \\
\hline 2020 & 63 & 5.1 \\
\hline 2019 & 62 & 5.0 \\
\hline 2018 & 57 & 4.6 \\
\hline 2017 & 54 & 4.4 \\
\hline 2016 & 57 & 4.6 \\
\hline 2015 & 66 & 5.3 \\
\hline 2014 & 62 & 5.0 \\
\hline 2013 & 44 & 3.5 \\
\hline 2012 & 53 & 4.3 \\
\hline 2011 & 55 & 4.4 \\
\hline 2010 & 54 & 4.4 \\
\hline 2009 & 48 & 3.9 \\
\hline 2008 & 53 & 4.3 \\
\hline 2007 & 47 & 3.8 \\
\hline 2006 & 45 & 3.6 \\
\hline 2005 & 36 & 2.9 \\
\hline 2004 & 37 & 3.0 \\
\hline 2003 & 44 & 3.5 \\
\hline 2002 & 29 & 2.3 \\
\hline 2001 & 31 & 2.5 \\
\hline 2000 & 39 & 3.1 \\
\hline 1999 & 28 & 2.3 \\
\hline 1998 & 33 & 2.7 \\
\hline 1997 & 35 & 2.8 \\
\hline 1996 & 13 & 1.0 \\
\hline 1995 & 15 & 1.2 \\
\hline 1994 & 20 & 1.6 \\
\hline 1993 & 18 & 1.5 \\
\hline 1992 & 10 & 0.8 \\
\hline 1991 & 13 & 1.0 \\
\hline 1990 & 2 & 0.2 \\
\hline 1989 & 1 & 0.1 \\
\hline 1988 & 1 & 0.1 \\
\hline 1986 & 1 & 0.1 \\
\hline 1975 & 1 & 0.1 \\
\hline 1973 & 1 & 0.1 \\
\hline
\end{tabular}

Actual number of literature published each year shown.
In general, the number of publications increased annually. These 1,241 literatures were cited 27,149 times in total, and each document was cited 21.88 times on average; the h-index count was 77 (Figure 2).

\section{Distribution of the countries and research institutions of the source of the literature}

CiteSpace software was used to analyze the retrieved literature and generate the country visualization map (Figure 3); the institution visualization map (Figure 4). The top 5 countries for the number of literatures published were the USA, Turkey, Italy, South Korea, and China. The top 5 countries for literature centrality were the USA, Germany, Italy, Canada, and China (Tables 3,4). In Figure 3, the nodes of countries were few, indicating that there were few countries were involved in the field. but the leading countries have many connections with other countries, suggesting that this field is concentrated in a few countries, and there is more cooperation among these countries compared with other countries (Figure 3). The number of literature from each institution was generally less than 10 , and the centrality score was low, only 4 institutions have centrality score of 0.01 , indicating that the research in this field was relatively scattered among institutions and there was little cooperation between these institutions (Tables 5,6).

\section{Author distribution}

As seen in Figure 5, there were few links between authors, and the related literature published by each author was also few. The top authors by number of publications were mainly from South Korea (Table 7). The authors' centrality score did not reach 0.01 (data not shown), suggesting that there was less cooperation between authors. In terms of literature citations, the most cited authors were mainly from Denmark (Laszlo Hegedüs), the USA (Hossein Gharib), Finland (Antti E. E. Brander), and other European and American countries. South Korean authors published most articles; however, the number of citations was relatively low (Figure 6; Tables 8,9).

\section{Distribution of journals}

The 1,241 articles in the present study are from 451 journals, of which 22 journals published more than 10 articles (Table 10), with a total of 415 articles published, accounting for $33.4 \%$ of the total literature (Table 9). 


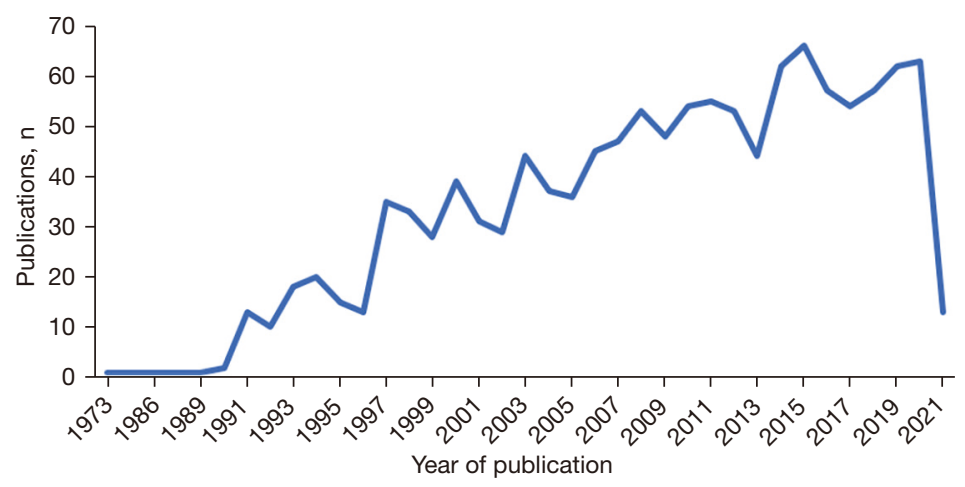

Figure 1 Annual trends in the number of papers published.

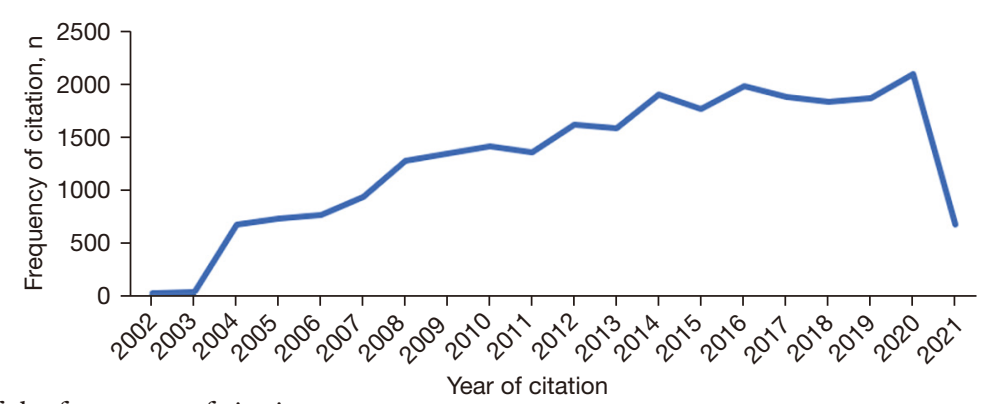

Figure 2 The annual trend of the frequency of citations.

$$
\text { Year of citation }
$$

Figure 3 Country visualization map the co-operation in researches.

According to the results in the Tables 10-12, it is inferred that journals such as Thyroid, Journal of Clinical Ultrasound, and Journal of Endocrinological Investigation, have greater influence in this field.

\section{Keyword analysis}

CiteSpace software was used to construct a keyword cooccurrence map (Figure 7). The top 10 keywords in terms of frequency and centrality are listed in Tables 13,14. 


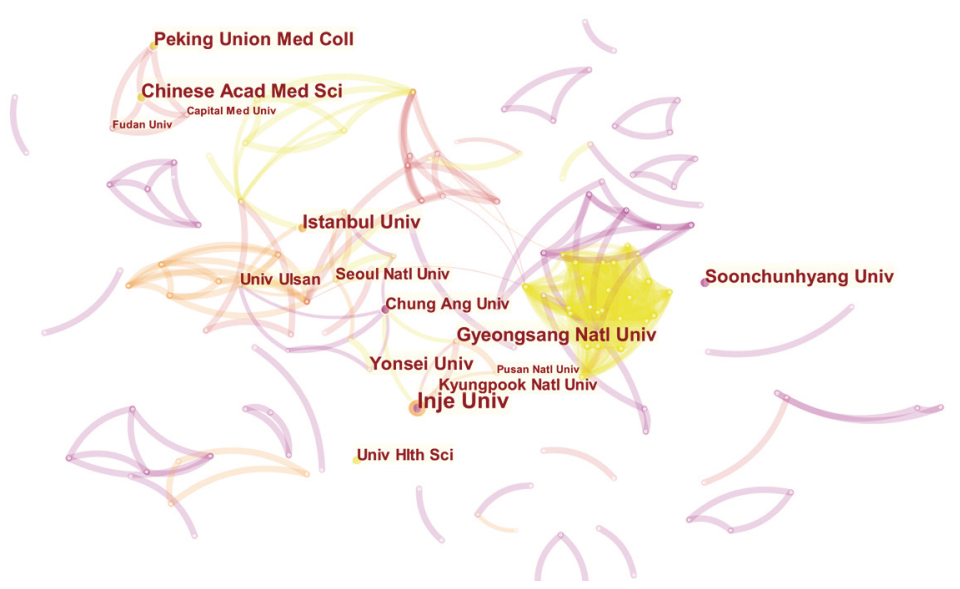

Figure 4 Institution visualization map showed the co-operation in researches

Table 3 Top 10 countries in terms of number of publications

\begin{tabular}{llc}
\hline Rank & Countries & Publications $(\mathrm{n})$ \\
\hline 1 & USA & 173 \\
2 & Turkey & 134 \\
3 & Italy & 129 \\
4 & South Korea & 116 \\
5 & China & 104 \\
6 & Japan & 103 \\
7 & Germany & 92 \\
8 & France & 48 \\
9 & Brazil & 39 \\
10 & Poland & 32 \\
\hline
\end{tabular}

Table 4 Top 10 countries for centrality

\begin{tabular}{llc}
\hline Rank & Countries & Centrality score \\
\hline 1 & USA & 0.46 \\
2 & Germany & 0.23 \\
3 & Italy & 0.20 \\
4 & Canada & 0.11 \\
5 & China & 0.10 \\
6 & Brazil & 0.09 \\
7 & England & 0.09 \\
8 & Sweden & 0.06 \\
9 & The Netherlands & 0.05 \\
10 & Belgium & 0.04 \\
\hline
\end{tabular}

Table 6 Top 4 research institutions in terms of centrality

\begin{tabular}{lllc}
\hline Rank & Institution & Country & Centrality score \\
\hline 1 & University of Perugia & Italy & 0.01 \\
2 & University of Milan & Italy & 0.01 \\
3 & Paula Stradina Clinical & Latvia & 0.01 \\
& University Hospital & & 0.01 \\
4 & Sapienza University of & Italy & \\
\hline
\end{tabular}

Table 5 Top 10 institutions in terms of number of publications

\begin{tabular}{llc}
\hline Rank & Institution & Publications (n) \\
\hline 1 & Inje University & 9 \\
2 & Gyeongsang National University & 6 \\
3 & Chinese Academy of Medical Science & 6 \\
4 & Istanbul University & 6 \\
5 & Yonsei University & 5 \\
6 & Soonchunhyang University & 5 \\
7 & Peking Union Medical College & 5 \\
8 & University of Ulsan & 4 \\
9 & Seoul National University & 4 \\
10 & Chung Ang University & 4 \\
\hline
\end{tabular}




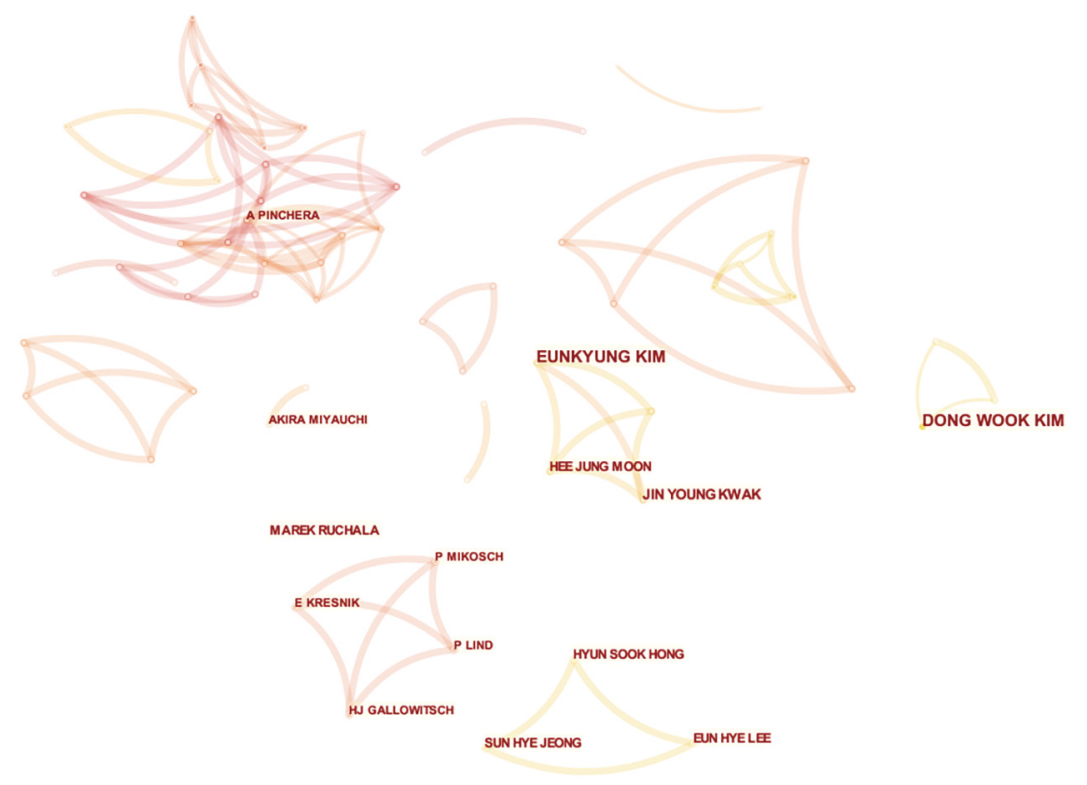

Figure 5 Co-author visualization map showed that the co-operation in researches.

Table 7 Top 10 authors by number of literatures published

\begin{tabular}{llc}
\hline Rank & Author & Publications $(\mathrm{n})$ \\
\hline 1 & Dong Wook Kim & 11 \\
2 & Eunkyung Kim & 10 \\
3 & Jin Young Kwak & 8 \\
4 & Marek Ruchala & 6 \\
5 & Hyun Sook Hong & 6 \\
6 & Sun Hye Jeong & 6 \\
7 & Eun Hye Lee & 6 \\
8 & Hee Jung Moon & 6 \\
9 & Akira Miyauchi & 5 \\
10 & E. Kresnik & 5 \\
\hline
\end{tabular}

In addition to ultrasonography and thyroid gland, high-frequency keywords were elasticity, carcinoma, management, and nodule. The centrality results suggest that the focus of thyroid ultrasound research is ultrasonography and management (Table 14). For keywords with high frequency of use, CiteSpace is used for burst detection. The results are shown in Figure 8. It can be seen that the highfrequency keywords have gradually evolved from the initial "tumor" the current "guideline".

\section{Discussion}

The findings of the present study indicated that there are not many publications on ultrasonography and thyroid gland. Although the overall trend is increasing, there are fluctuations, suggesting that there is a certain degree of inconsistency in the research in this field. Some scholars believe that this field is worthy of in-depth and extensive research, while others believe that too much research may be of little value to clinical practice. This is also consistent with the author's point of view in some studies $(9,12)$. Although Asian countries have published more relevant publications, the countries with higher centrality are mainly European countries, including Italy, German, France, and the USA, and although the number of publications published by Korean authors is higher, the number of citations is significantly lower than that of European and US scholars. There were no Korean or Chinese scholars among the top 10 authors, which means that most important research comes from research institutions in Europe and the USA. We also found that the number of relevant publications in this field by major researchers was relatively small, and Dong Wook Kim, who has the highest number of publications, only published 11 articles, indicating that there is less research in this field compared with other fields. Although the number of literature published in ultrasound journals was high, the 


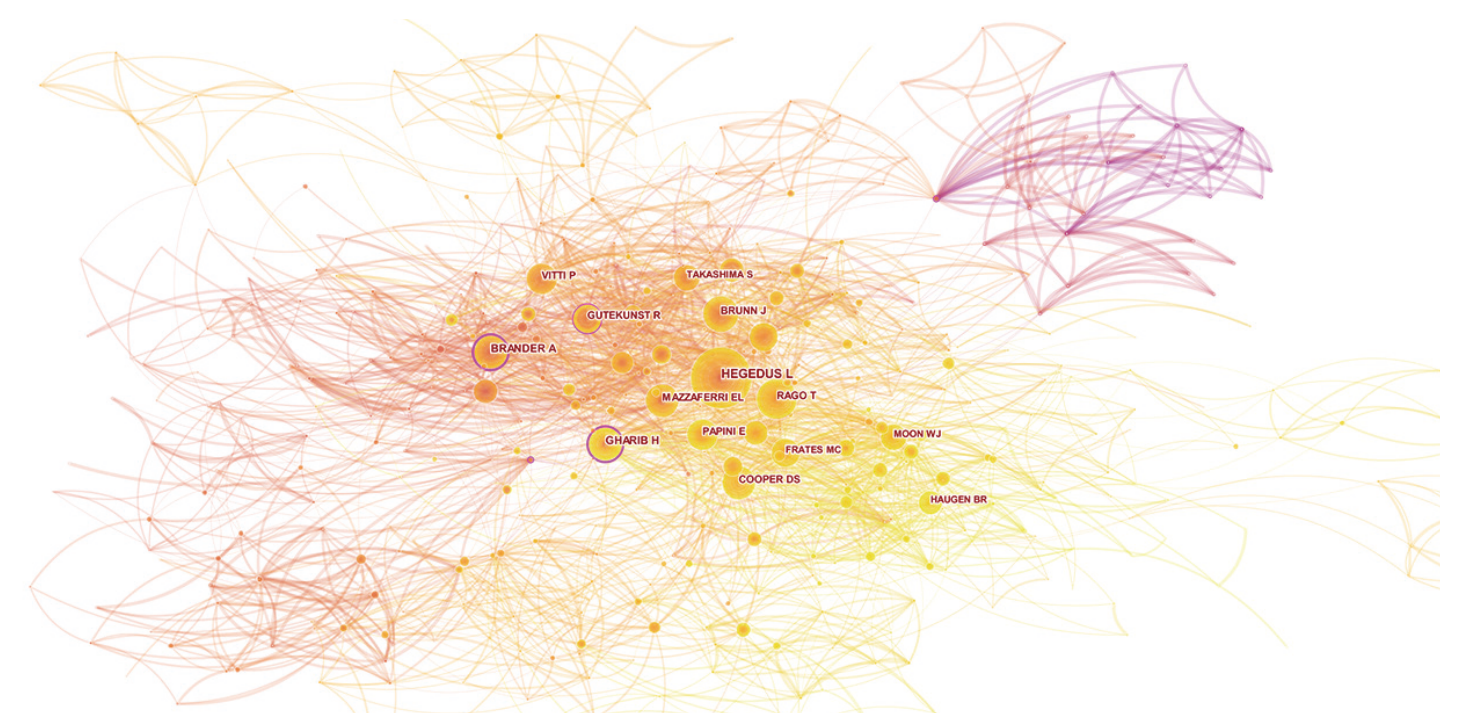

Figure 6 Author co-cited visualization map showed authors been cited in literatures.

Table 8 Top 10 most cited authors by the number of citations

\begin{tabular}{llc}
\hline Rank & Author & Frequency (n) \\
\hline 1 & Laszlo Hegedüs & 126 \\
2 & Hossein Gharib & 75 \\
3 & Antti E. E. Brander & 73 \\
4 & Juergen Brunn & 70 \\
5 & Teresa Rago & 67 \\
6 & David S. Cooper & 66 \\
7 & Ernest L. Mazzaferri & 65 \\
8 & R. W. Gutekunst & 55 \\
9 & Enrico Papini & 55 \\
10 & Paolo Vitti & 55 \\
\hline
\end{tabular}

most frequently cited journals were endocrinology journals, suggesting that the relevant literature in these journals warrant further attention. Keyword analysis results showed that although high-frequency keywords have changed, the focus is still in the identification and monitoring of benign and malignant nodules, and that the main clinical value of thyroid ultrasound is in the discovery and identification of thyroid nodules. Overall, the findings of the present study indicate that the study of thyroid ultrasound need to be improved.

Ultrasonography is convenient, cheap, and noninvasive (14). By thorough and careful examination of
Table 9 Top 10 centrally cited authors

\begin{tabular}{llc}
\hline Rank & Author & Centrality score \\
\hline 1 & Antti E. E. Brander & 0.24 \\
2 & Hossein Gharib & 0.21 \\
3 & R. W. Gutekunst & 0.12 \\
4 & Gretchen A. W. Gooding & 0.12 \\
5 & Manuel R. Blum & 0.12 \\
6 & Teresa Rago & 0.10 \\
7 & Luigi Solbiati & 0.09 \\
8 & Satoshi Takashima & 0.08 \\
9 & Laszlo Hegedüs & 0.07 \\
10 & David S. Cooper & 0.07 \\
\hline
\end{tabular}

thyroid and adjacent lymph nodes, ultrasonography can diagnose most thyroid nodules (14). In clinical practice, clinician can differentiate benign and malignant lesions and active and inactive nodules by number of lesions (nodules), position, anteroposterior to transverse diameter ration, wall configuration, acoustic halo and internal echo (9). Besides, ultrasound guided fine needle aspiration biopsy was widely used in surgical practice $(9,15)$. And with the precise ultrasound guidance, thermal ablation, radiofrequency ablation, laser ablation, microwave ablation and high-intensity focused ultrasound ablation, was also effectively used in the treatment of thyroid nodules (15). 
Table 10 Top 22 journals by number of articles published

\begin{tabular}{|c|c|c|c|}
\hline Rank & Journal & Number of records & Percentage of 1,241 \\
\hline 2 & Journal of Clinical Ultrasound & 35 & 2.8 \\
\hline 3 & Journal of Endocrinological Investigation & 28 & 2.3 \\
\hline 4 & Clinical Endocrinology & 26 & 2.1 \\
\hline 6 & Endocrine Journal & 19 & 1.5 \\
\hline 7 & Journal of Clinical Endocrinology Metabolism & 19 & 1.5 \\
\hline 8 & Surgery & 18 & 1.5 \\
\hline 9 & Clinical Nuclear Medicine & 17 & 1.4 \\
\hline 12 & Medicine & 15 & 1.2 \\
\hline 13 & Veterinary Radiology Ultrasound & 15 & 1.2 \\
\hline 14 & Journal of Pediatric Endocrinology Metabolism & 14 & 1.1 \\
\hline 15 & Annales d'Endocrinologie & 12 & 1.0 \\
\hline 16 & Endocrine & 12 & 1.0 \\
\hline 17 & Experimental and Clinical Endocrinology Diabetes & 12 & 1.0 \\
\hline 18 & American Journal of Roentgenology & 11 & 0.9 \\
\hline 19 & Korean Journal of Radiology & 11 & 0.9 \\
\hline
\end{tabular}

Table 11 Top journals by citation

\begin{tabular}{llc}
\hline Rank & Journal & Frequency (n) \\
\hline 1 & $\begin{array}{l}\text { Journal of Clinical Endocrinology \& } \\
\text { Metabolism }\end{array}$ & 694 \\
2 & Thyroid & 648 \\
3 & Clinical Endocrinology & 402 \\
4 & Radiology & 370 \\
5 & Surgery & 350 \\
6 & American Journal of Roentgenology & 339 \\
7 & World Journal of Surgery & 333 \\
8 & European Journal of Endocrinology & 330 \\
9 & New England Journal of Medicine & 299 \\
10 & Journal of Endocrinology Investigation & 289 \\
\hline
\end{tabular}

Table 12 Top 10 journals by centrality score

\begin{tabular}{llc}
\hline Rank & Journal & Centrality score \\
\hline 1 & Journal of Clinical Ultrasound & 0.15 \\
2 & Annals of Internal Medicine & 0.13 \\
3 & Journal of Clinical Endocrinology \& & 0.09 \\
& Metabolism \\
4 & American Journal of Roentgenology & 0.09 \\
5 & Cancer & 0.09 \\
6 & Radiology & 0.07 \\
7 & Surgery & 0.07 \\
8 & New England Journal of Medicine & 0.07 \\
9 & Journal of Ultrasound Medicine & 0.07 \\
10 & Annals of Surgery & 0.07 \\
\hline
\end{tabular}




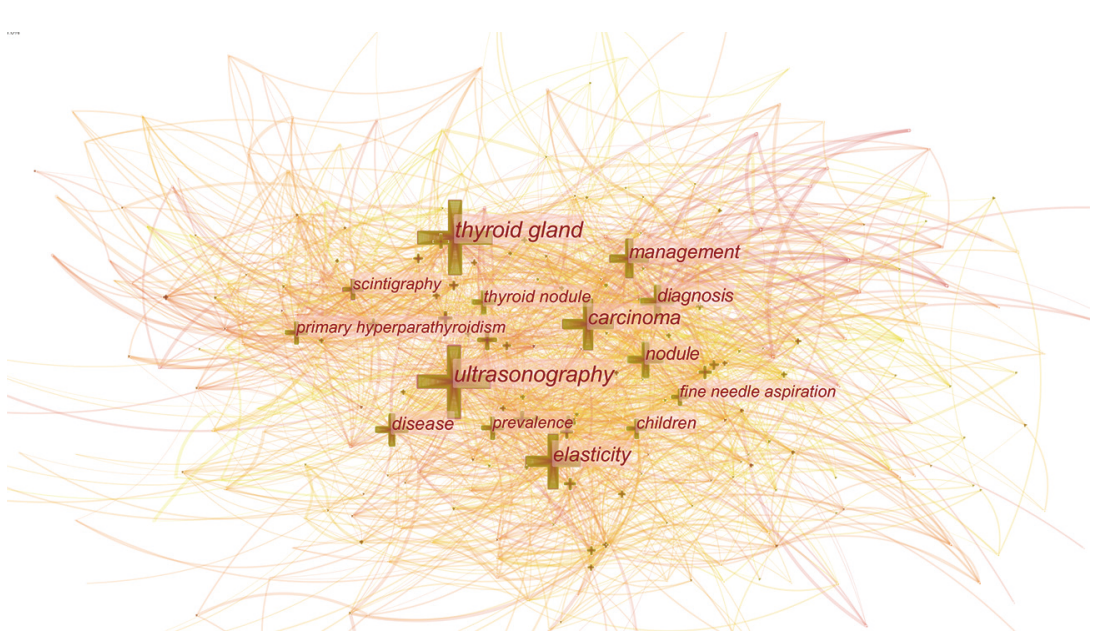

Figure 7 Keyword co-occurrence map showed that the most used keywords and the relationship between keywords.

Table 13 Top 10 frequently used keywords

\begin{tabular}{llc}
\hline Rank & Keyword & Frequency $(\mathrm{n})$ \\
\hline 1 & Ultrasonography & 522 \\
2 & Thyroid gland & 514 \\
3 & Elasticity & 287 \\
4 & Carcinoma & 268 \\
5 & Management & 194 \\
6 & Nodule & 168 \\
7 & Diagnosis & 161 \\
8 & Disease & 139 \\
9 & Thyroid nodule & 99 \\
10 & Children & 96 \\
\hline
\end{tabular}

Except for ultrasound characteristics, there were some clinical characteristics suggesting malignant thyroid nodules, including younger age (30-49 years old), obesity, high dietary iodine intake (15). The disadvantage of ultrasonography is that the judgment of the nature of the lesion is often not very accurate (16). The ultrasonography result has a great relationship with the patient's physical condition, the lesion and its surrounding anatomy, the examiner's experience, and the performance of the instrument. The results obtained for the same patient by the same examiner at different times may have obvious difference $(17,18)$. With the widespread use of thyroid ultrasound, many studies have found that a large number of thyroid ultrasound examinations can be avoided, which
Table 14 Top 10 keywords for centrality

\begin{tabular}{llc}
\hline Rank & Keyword & Centrality score \\
\hline 1 & Ultrasonography & 0.24 \\
2 & Thyroid gland & 0.16 \\
3 & Elasticity & 0.13 \\
4 & Carcinoma & 0.12 \\
5 & Scintigraphy & 0.11 \\
6 & Management & 0.10 \\
7 & Diagnosis & 0.10 \\
8 & Children & 0.10 \\
9 & Disease & 0.08 \\
10 & Nodule & 0.07 \\
\hline
\end{tabular}

can reduce medical expenses, optimize the rational use of examination resources, and reduce patient burden, including economic, psychological, and physical burden during long-term follow-up periods (10). For some highrisk patients, such as patients with familial adenomatous polyposis, it may not be necessary to have an annual thyroid ultrasound examination, and it might be more reasonable to have a thyroid ultrasound examination every 2 years (19).

The incidence of thyroid nodules increases with age, especially in women, iodine deficiency patients, and those exposed to radiation. However, the clinical prevalence has a lot to do with the examination method: the prevalence of thyroid nodules diagnosed by doctors is about $2-6 \%$, 
Top 25 keywords with the strongest citation bursts

$\begin{array}{lrrrl}\text { Keywords } & \text { Year Strength Begin End } \\ \text { Adenoma } & 1973 & 10.31 & 1993 & 2000 \\ \text { Tumor } & 1973 & 4.6 & 1993 & 1998 \\ \text { Thyroid disease } & 1973 & 4.09 & 1993 & 2007 \\ \text { Therapy } & 1973 & 5.41 & 1994 & 2005 \\ \text { Localization } & 1973 & 4 & 1994 & 2007 \\ \text { Technetium 99m sestamibi } & 1973 & 7.33 & 1996 & 2000 \\ \text { Hyperparathyroidism } & 1973 & 5.86 & 1997 & 2006 \\ \text { Double phase } & 1973 & 4.69 & 1997 & 2000 \\ \text { Goiter } & 1973 & 6.21 & 2000 & 2009 \\ \text { lodine deficiency } & 1973 & 5.76 & 2002 & 2006 \\ \text { Parathyroid gland } & 1973 & 5.41 & 2003 & 2009 \\ \text { Thyroid cancer } & 1973 & 5.22 & 2006 & 2010 \\ \text { Minimally invasive parathyroidectomy } & 1973 & 4.99 & 2006 & 2011 \\ \text { Surgery } & 1973 & 4.88 & 2006 & 2015 \\ \text { High resolution ultrasonography } & 1973 & 4.31 & 2006 & 2008 \\ \text { Of the literature } & 1973 & 4.11 & 2008 & 2013 \\ \text { Surgical management } & 1973 & 3.98 & 2008 & 2014 \\ \text { Malignancy } & 1973 & 5.32 & 2009 & 2015 \\ \text { Benign } & 1973 & 9.89 & 2013 & 2021 \\ \text { Hashimoto thyroiditis } & 1973 & 5.05 & 2013 & 2018 \\ \text { Thyroid volume } & 1973 & 4.24 & 2014 & 2015 \\ \text { Feature } & 1973 & 5.57 & 2017 & 2021 \\ \text { Association guideline } & 1973 & 4.9 & 2017 & 2019 \\ \text { Differentiation } & 1973 & 5.04 & 2018 & 2021 \\ \text { Guideline } & 1973 & 5.67 & 2019 & 2021 \\ & & & \end{array}$

Figure 8 Burst analysis showed that the utility of key words changed annually.

and prevalence determined by ultrasound examination is about $19-35 \%$, while the prevalence determined by biopsy is about $8-65 \%$, with significant fluctuations between different studies. With the improvement in ultrasound equipment, the number of diagnosis of thyroid nodules and even thyroid cancer has increased significantly (1). With the promotion and improvement of public health work, the problem of iodine deficiency has been significantly improved in many areas $(1,20)$, and the incidence of thyroid nodules related to iodine deficiency has been significantly reduced (21). Therefore, many scholars believe that the increase in the number of patients with thyroid nodules is due to the overuse of thyroid ultrasound. When thyroid nodule is diagnosed, it will cause a certain psychological burden to the patient (22). Many researchers currently believe that patients with thyroid cancer generally have a good prognosis, and the main problem is great burden on the patient's psychology $(23,24)$. Therefore, for benign thyroid nodules or thyroid cancer, it needs more evidence to clarify whether ultrasound is really beneficial.

The present study has some limitations. Subject search may miss some documents closely related to the field, the reason may be that "ultrasonography" and "thyroid" are not the subjects of some document. However, we conducted an in-depth analysis of the literature and found that important research in this field, especially the highly cited literature. Future research should improve the search strategy, remove duplicate publications and reduce omissions, so as to fully demonstrate the current status of research in this field.

\section{Acknowledgments}

Funding: None.

\section{Footnote}

Conflicts of Interest: All authors have completed the ICMJE uniform disclosure form (available at https://dx.doi. org/10.21037/gs-21-799). The authors have no conflicts of interest to declare.

Ethical Statement: The authors are accountable for all aspects of the work in ensuring that questions related to the accuracy or integrity of any part of the work are appropriately investigated and resolved.

Open Access Statement: This is an Open Access article distributed in accordance with the Creative Commons Attribution-NonCommercial-NoDerivs 4.0 International License (CC BY-NC-ND 4.0), which permits the noncommercial replication and distribution of the article with the strict proviso that no changes or edits are made and the 
original work is properly cited (including links to both the formal publication through the relevant DOI and the license). See: https://creativecommons.org/licenses/by-nc-nd/4.0/.

\section{References}

1. Dean DS, Gharib H. Epidemiology of thyroid nodules. Best Pract Res Clin Endocrinol Metab 2008;22:901-11.

2. Wouters HJCM, Slagter SN, Muller Kobold AC, et al. Epidemiology of thyroid disorders in the Lifelines Cohort Study (the Netherlands). PLoS One 2020;15:e242795.

3. Durante C, Costante G, Lucisano G, et al. The natural history of benign thyroid nodules. JAMA 2015;313:926-35.

4. Kundra A, Goldstein DP, Wintemute K, et al. A pilot study examining Toronto-area family physician perspectives on thyroid neoplasm evaluation. J Otolaryngol Head Neck Surg 2019;48:24.

5. Wang L, Zhang L, Zhu M, et al. Automatic diagnosis for thyroid nodules in ultrasound images by deep neural networks. Med Image Anal 2020;61:101665.

6. Park JW, Kim DW, Kim D, et al. Korean Thyroid Imaging Reporting and Data System features of follicular thyroid adenoma and carcinoma: a single-center study. Ultrasonography 2017;36:349-54.

7. Lin M, Su Y, Huang Y, et al. Ultrasonographic evaluation of extracapsular vascular invasion for subcapsular nodules of the thyroid. Transl Cancer Res 2020;9:6464-70.

8. Jun JK, Hwang SY, Hong S, et al. Association of Screening by Thyroid Ultrasonography with Mortality in Thyroid Cancer: A Case-Control Study Using Data from Two National Surveys. Thyroid 2020;30:396-400.

9. Gamme G, Parrington T, Wiebe E, et al. The utility of thyroid ultrasonography in the management of thyroid nodules. Can J Surg 2017;60:134-9.

10. Davenport C, Alderson J, Yu IG, et al. A review of the propriety of thyroid ultrasound referrals and their followup burden. Endocrine 2019;65:595-600.

11. Shalaby M, Hadedeya D, Lee GS, et al. Impact of Surgeon-Performed Ultrasound on Treatment of Thyroid Cancer Patients. Am Surg 2020;86:1148-52.

Cite this article as: Su J, Gao G, Xu H. Bibliometric analysis of research on thyroid ultrasonography. Gland Surg 2021;10(12):3283-3293. doi: 10.21037/gs-21-799
12. Klubo-Gwiezdzinska J, Yang L, Merkel R, et al. Results of Screening in Familial Non-Medullary Thyroid Cancer. Thyroid 2017;27:1017-24.

13. White HD, Lin X, Buzydlowski JW, et al. User-controlled mapping of significant literatures. Proc Natl Acad Sci U S A 2004;101 Suppl 1:5297-302.

14. Hart JL, Lloyd C, Harvey CJ. Ultrasound of the thyroid. Br J Hosp Med (Lond) 2008;69:M68-71.

15. Durante C, Grani G, Lamartina L, et al. The Diagnosis and Management of Thyroid Nodules: A Review. JAMA 2018;319:914-24.

16. Ahn HS, Lee JB, Seo M, et al. Distinguishing benign from malignant thyroid nodules using thyroid ultrasonography: utility of adding superb microvascular imaging and elastography. Radiol Med 2018;123:260-70.

17. Leidi A, Rouyer F, Marti C, et al. Point of care ultrasonography from the emergency department to the internal medicine ward: current trends and perspectives. Intern Emerg Med 2020;15:395-408.

18. Merritt CR, Carroll BA, Cooperberg PL, et al. Ultrasonography. Radiology 1994;190:610-3.

19. Monachese M, Mankaney G, Lopez R, et al. Outcome of thyroid ultrasound screening in FAP patients with a normal baseline exam. Fam Cancer 2019;18:75-82.

20. Teng $W$, Shan $Z$, Teng $X$, et al. Effect of iodine intake on thyroid diseases in China. N Engl J Med 2006;354:2783-93.

21. Zimmermann MB. Thyroid gland: Iodine deficiency and thyroid nodules. Nat Rev Endocrinol 2014;10:707-8.

22. Singhai A, Panda S. Small Thyroid Nodule but Big Impact. Adv Biomed Res 2020;9:23.

23. Bresner L, Banach R, Rodin G, et al. Cancer-related worry in Canadian thyroid cancer survivors. J Clin Endocrinol Metab 2015;100:977-85.

24. Papaleontiou M, Reyes-Gastelum D, Gay BL, et al. Worry in Thyroid Cancer Survivors with a Favorable Prognosis. Thyroid 2019;29:1080-8.

(English Language Editor: J. Gray) 